der Reaction durch Vermehrung des letzteren unter Umständen sehr erhöhen lässt. Gladisz und Balo führten die betreffenden Versuche über diesen Gegenstand in der Weise aus, dass sie die eine Hälfte einer in gewöhnlicher Temperatur gesättigten Weinsäurelösung durch kohlensaures Natron neutralisirten, hierauf mit der anderen Hälfte vermischten und von der so erhaltenen Flüssigkeit verschiedene Mengen zu $10 \mathrm{CC}$. einer Salpeterlösung hinzufügten, welche durch Auflösen von $50 \mathrm{Grm}$. Kalisalpeter in $500 \mathrm{CC}$. Wasser erhalten worden war, und schüttelten. Die nach etwa 24 Stunden vom niedergefallenen sauren weinsauren Kali abfiltrirte Flüssigkeit wurde eingedampft, der Rückstand geglüht, in Salzsäure gelöst, mit Weingeist und Platinchlorid versetzt und das gebildete Kalium-Platinchlorid unter den bekannten Vorsichtsmaassregeln bestimmt. Die aus demselben erhaltenen Platinmengen entsprachen bei Anwendung von 20 CC. des Reagens 2,5 bis 2,35 , bei 30 CC. 1,80 bis 1,82 , bei 50 CC. 1,1 pCt. des angewandten Salpeters. Als 5 CC. der Salpeterlösung und $50 \mathrm{CC}$. des Reagens angewandt worden waren, zeigte sich nach 48stündigem Stehen in der erwähnten Mischung von Weingeist, Chlorplatin und der salzsauren Lösung kein Niederschlag. Eine gesättigte Weinsteinlösung wurde alsbald gefällt, als ihr von der gesättigten Lösung des sauren Natronsalzes etwas zugefügt wurde. Bolley ist nun der Ansicht, dass sich die in Rede stehende Thatsache allerdings vielleicht zur quantitativen Bestimmung des Kaligehaltes im Salpeter bei Analysen für technische Zwecke benutzen lasse, wenn es gelingen sollte, eine Methode aufzufinden, um die dem Weinsteinniederschlage anhaftende Menge des sauren weinsauren Natrons $z \mathfrak{u}$ entfernen oder der Menge nach genau zu bestimmen.

\title{
Ueber die Bestimmung des Kohlenstoffs im Roheisen, Stabeisen
} und Stahl. Um das Eisen zum Zwecke der Kohlenstoffbestimmung als Chlorür aufzulösen und dabei sicher zu sein, dass keine Spur eines Gases sich entwickelt, welches einen Theil des Kohlenstofis entführen könnte, wendet Boussing a ult*) Quecksilberchlorid an. Das pulverisirte Roheisen wird mit dem 15fachen Gewichte Quecksilberchlorid und Wasser zu einem dünnen Brei angemacht und eine halbe Stunde lang im Achatmörser, oder falls man die Beimengung einer geringen Kieselsäuremenge nicht zu scheuen braucht, im Glasmörser zerrieben. Nach Zusatz von Wasser wird das Ganze in ein Becherglas gebracht und eine Stunde lang in einer Temperatur von 80 bis $100^{9}$ gehalten. Hierauf wird filtrirt und der mit heissem Wasser gewaschene Rückstand, nach völligem Aus-

\footnotetext{
*) Compt. rend. Bd. 66. p. 873.
} 
trocknen im Luftbade, in einem Platinschiffchen in einem Strome trockenen Wasserstoffgases nach und nach bis zur Rothgluth erhizt, worauf sich das entstandene Quecksilberchlorür unzersetzt, oder nur unter Abscheidung einer sehr geringen Quecksilbermenge verflüchtigt. Die Anwendung von Wasserstoff ist hierbei der von Stickstoff vorzuziehen, weil letzterer nicht so leicht in einem constanten Strome und auch nicht so leicht sauerstofffrei erhalten werden kann, wie ersteres Gas, welches der Verfasser durch eine längere Schicht von Platinschwamm leitete und es dadurch frei von Arsen und anch völig frei von Sauerstoff erhielt. Nach der Verflüchtigung des Quecksilberchlorürs und nach dem Erkalten im Wasserstoffgase wird das Schiffchen mit den bekannten Vorsichtsmaassregeln gewogen. Die darin befindliche Kohle von schön schwarzer Farbe, ist sehr voluminös, entzündet sich sehr leicht und verbrennt wie Zündschwamm, wenn sie ans weissem Roheisen oder aus Stabeisen oder aus Stahl erhalten war; der aus granem Roheisen zurückbleibende Graphit bedarf jedoch der Erhitzung im Sauerstoffgase. - Die beim Verbrennen zurückbleibende Asche wird im Wasserstoffstrome zum Rothglüheu erhitzt und gewogen. Dieselbe enthält stets Kieselsäure, selbst wenn sie aus Stahl oder Stabeisen; in denen man einen Gehalt an Schlacke nicht annehmen kann, erhalten worden ist. Diese Kieselsäure entsteht aus mit dem Eisen chemisch verbundenem Silicium, indem letzteres durch das Quecksilberchlorid in Chlorsilicium verwandelt wird, welches unter dem Einfluss des Wassers Kieselsäure bildet. Ein Theil dieser Säure bleibt jedoch dabei in Lösung, so dass die in der Asche gefundene Menge nicht der ganzen, vorhanden gewesenen Siliciummenge entspricht. Um der Pulverisirung des Eisens, welche bei grauem Roheisen, bei Stahl und Stabeisen die Anwendung von Säge und Feile erfordert, überhoben zu sein, versuchte Damour die Umwandlung des Eisens in Chlorür, ohne dasselbe vorher zu zerkleinern. Er stellte einen, 1,06 Grm. wiegenden Stahlcylinder in eine aus Platindraht gefertigte Spirale, hing ihn darauf in eine Quecksilberchloridlösung, welche nun in einen Trockenschrank placirt wurde. Nach Verlauf von zwei Tagen war der Stahlcylinder aufgelöst. - Hiernach fand Boussingault auch, dass die Zerkleinerung des Metalls bis zu feinem Pulver überflüssig ist. Man braucht vom Stahl nur Späne auf der Drehbank herzustellen, um sicher zu sein, dass die Umwandlung von $1 \mathrm{Grm}$. des Metalls in Chlorür bei halbstündigem Reiben mit Quecksilberchlorid vollendet wird.

Das Verfahren" des Verfassers wird jetzt im "Conservatoire des arts et des métiers" in Paris bei Bestimmung des Kohlenstoffes in Gusseisen und Stahl stets angewendet. 